\title{
Coronavirus and the Future of a Welfare State
}

Oksana V. Sinyavskaya

\author{
Oksana V. Sinyavskaya, \\ Independent Institute for Social Policy, Moscow, Russia \\ Deputy Director; \\ Higher School of Economics, Moscow, Russia \\ Department of World Economy and International Affairs \\ Associate Professor
}

SPIN RSCI: 8837-6167

ORCID: 0000-0002-6044-0732

ResearcherID: K-2581-2015

Scopus AuthorID: 35362676900

This article is an abridged version of the paper written for the Valdai Discussion Club. The original version is available at: https://valdaiclub.com/a/highlights/from-a-welfare-stateto-a-welfare-society/?sphrase_id=662755

DOI: $10.31278 / 1810-6374-2020-18-2-43-47$

A society that allows glaring inequality is likely to pay a higher price for getting out of the crisis caused by the pandemic, a Valdai Club expert says. This means more deaths, greater impoverishment risks for a part of the population, and most likely a deeper crisis. So, addressing the problem of excessive income inequality is a prerogative for more than just social policy.

After several decades of talk about the imminent collapse of welfare states and the triumph of the market economy, what we have seen in recent months
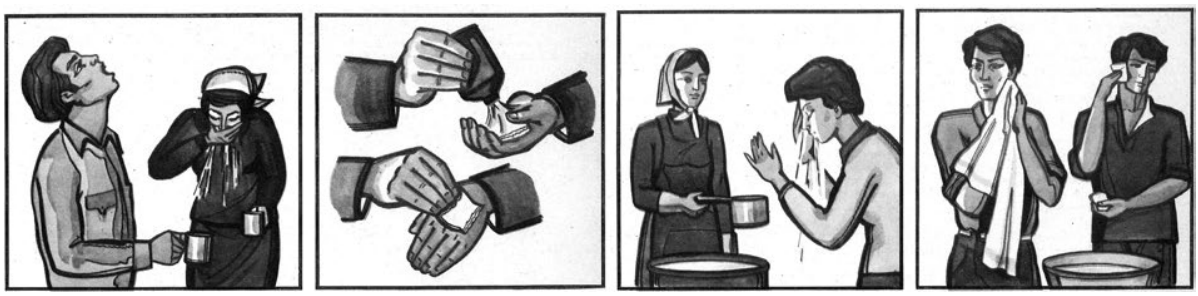
could be called a renaissance of state paternalism. More and more countries are introducing measures to support enterprises and citizens, lowering taxes, and dipping into stabilization and reserve funds, thus increasing public debt. In other words, they are doing what seemed utterly impossible before the current emergency situation.

The very fact that in order to save human lives from a new disease states are ready to give up their current economic interests indicates that over the past century the protection of health as a human right has become an integral part of the social contract. The value of this guarantee is considered no less important than protection from an external enemy. Moreover, as the reaction to the coronavirus outbreak has shown, this is true of Asian countries as well; the approach is not unique to the Western world. This did not happen, for example, a hundred years ago, when the Spanish flu raged.

Does this mean that all talk about the uselessness of welfare state will stop after the end of the pandemic? I am sure it will not. When the threat of mass deaths recedes, and economic difficulties, on the contrary, escalate, the governments of many countries will probably again start talking about the need to cut social spending, tighten access to social programs, reduce benefits and provide them more selectively, all in the name of state budgets and the economy.

How radical these reversals are going to be will largely depend on the respective countries' pre-crisis level of development and how efficiently they have managed to cope with the coronavirus crisis: many states will have fewer resources due to the duration and severity of the pandemic. States which have sustained heavier casualties and greater job and income losses due to extended quarantines will be more likely to "tighten their belts" and attempt to extricate themselves from the economic crisis at the expense of their citizens.

It must be kept in mind that two big threats to welfare states-the aging of the populations and the technological revolution-have not gone away. Therefore, the coronavirus pandemic will not change the long-term trend towards governments' rethinking social spending obligations.

Meanwhile, if we step aside from a purely fiscal perception of social policy, we will see several important lessons of the current crisis that can set vectors for the transformation of welfare states in the 21st century. 
The first thing that becomes obvious due to the specific nature of the coronavirus pandemic is demand for a new model of medicine and a new model of aging. The pandemic has not only exposed weaknesses in health care systems and tested their ability to promptly respond to emergencies. The high mortality rate among people with coronavirus from complications associated with various chronic diseases casts doubt on the effectiveness of the approach towards increasing life expectancy which prevailed at the end of the 20th century. In the current situation, it is no longer enough to prolong the lives of people with worsening health problems. It is important to learn to postpone the onset of these diseases and maintain the health of citizens to the oldest possible age. Therefore, anti-aging medicine, which appeared less than three decades ago and which aims to detect, prevent and treat agedependent diseases, will receive a powerful impetus for development.

It is important to emphasize that life extension is not limited solely to high-technology medical care and expensive services available to a chosen few. Studies show that lifestyle also contributes significantly to a person's health by way of nutrition, physical activity, sleep, stress levels, etc. And this opens up great opportunities for the state and non-state players to promote a healthy lifestyle and the concept of healthy longevity.

The second, and perhaps most important, issue that this pandemic has exposed is the high social cost of inequality. It would seem that all are equal before the virus as evidenced by coronavirus cases among politicians, famous actors, athletes, show business personalities, and other elite members of society. However, these are exceptions that do not change the general rule: the risks of contracting an infection, not receiving proper and timely treatment, and dying are obviously higher in the lower strata of society. The higher the level of income and property inequality in a country, and the more selective the coverage of social programs is there, the more pronounced these differences are likely to be, as borne out, for example, by the latest data from the United States.

There are several reasons for this. Firstly, high economic inequality is usually accompanied by significant inequalities in health and life expectancy. This means that at the same age, there will be more chronic diseases among people with low social status. Secondly, representatives of the lower social strata are often employed in the service sector or personal 
services: they work in the catering business or trade, as couriers, taxi drivers, housekeepers, caregivers, nannies, etc. So, during the pandemic they either continue to work, exposing themselves to a high risk of infection, or have lost their only source of income. Since more often than not they work unofficially, the availability of health services and social benefits for them largely depends on how much the state is ready to notice them. The quality of life during quarantine is incomparably higher in the upper social groups, where one has spacious housing, rainy day savings, and an online distance job. It can be assumed that elderly members of the upper class will not end up in nursing homes where old people get infected and die in large numbers, as is the case in France, Spain, and Italy.

Ultimately, a society that allows such high degrees of inequality is likely to pay a higher price for getting out of the crisis generated by the pandemic. It will face a large number of deaths, a greater risk of impoverishment of part of the population, and a deeper economic crisis.

Solving the problem of glaring inequality is not only the prerogative of social policy.

What is important for the future of welfare states is that the pandemic has highlighted the risks created by limited social support measures, including health services. It has increased demand for universal medical coverage and minimum social guarantees. It is no coincidence that many developed countries have expanded anti-crisis measures to cover people who previously were ignored, such as self-employed people, temporary workers, and contractors.

At the same time the current crisis has emphasized the benefits of universal welfare states. Among developed countries, Scandinavians have adopted the fewest number of new measures to support their citizens. This is not because they care less about their people. On the contrary, because of a large variety and broad coverage of existing social programs, which allow people from all walks of life to maintain a decent standard of living in various circumstances, these countries have no need to resort to extraordinary measures to address the current crisis. Their versatility and flexibility have insured them against force majeure circumstances.

The third lesson of the pandemic is one for social policy: welfare payments and state assistance are not enough to maintain an acceptable 
quality of life. Old people, people with disabilities, and single parents, who are essentially locked up at home, urgently need to have food and medicine delivered, and have to rely on the work of volunteers.

The lockdown has shown how important personal contacts and communication are for us. Although the virtual environment cannot replace real-life face-to-face communication, information technology has made it possible to offer new forms of mutual support. Various grassroots initiatives have been launched: self-help groups based on social networks, charitable educational programs for children (book reading, virtual tours, etc.), online broadcasts of performances and concerts-all these manifestations of solidarity help people endure home confinement.

Despite the extraordinary circumstances under which these projects have started, they have demonstrated the high ability of people, communities, and non-governmental organizations to organize themselves and jointly fill gaps in the quality of life. This is not the first, but a big step forward on the road from a welfare state to a welfare society based on the value of human life and shared recognition of the importance of its quality. 